\title{
Review
}

Garima Sharma' / Arti Parihar ${ }^{2}$ / Tanay Talaiya' / Kirti Dubey' / Bhagyesh Porwal ${ }^{1}$ / Mordhwaj S. Parihar ${ }^{3}$

\section{Cognitive impairments in type 2 diabetes, risk factors and preventive strategies}

\author{
${ }^{1}$ School of Studies in Zoology and Biotechnology, Vikram University, Ujjain, MP, India \\ ${ }^{2}$ Department of Science, Bellingham Technical College, Bellingham, WA, USA \\ ${ }^{3}$ School of Studies in Zoology and Biotechnology, Vikram University, Ujjain, MP, India, Phone: +91-734-2511317, E-mail: \\ mdsparihar@gmail.com. https://orcid.org/0000-0001-6955-8967.
}

\begin{abstract}
:
Mild cognitive impairment (MCI) is a modifiable risk factor in progression of several diseases including dementia and type 2 diabetes. If cognitive impairments are not reversed at an early stage of appearance of symptoms, then the prolonged pathogenesis can lead to dementia and Alzheimer's disease (AD). Therefore, it is necessary to detect the risk factors and mechanism of prevention of cognitive dysfunction at an early stage of disease. Poor lifestyle, age, hyperglycemia, hypercholesterolemia, and inflammation are some of the major risk factors that contribute to cognitive and memory impairments in diabetic patients. Mild cognitive impairment was seen in those individuals of type 2 diabetes, who are on an unhealthy diet. Physical inactivity, frequent alcohol consumptions, and use of packed food products that provides an excess of cheap calories are found associated with cognitive impairment and depression in diabetic patients. Omega fatty acids (FAs) and polyphenol-rich foods, especially flavonoids, can reduce the bad effects of an unhealthy lifestyle; therefore, the consumption of omega FAs and flavonoids may be beneficial in maintaining normal cognitive function. These functional foods may improve cognitive functions by targeting many enzymes and molecules in cells chiefly through their antiinflammatory, antioxidant, or signaling actions. Here, we provide the current concepts on the risk factors of cognitive impairments in type 2 diabetes and the mechanism of prevention, using omega FAs and bioactive compounds obtained from fruits and vegetables. The knowledge derived from such studies may assist physicians in managing the health care of patients with cognitive difficulties.
\end{abstract}

Keywords: age, hyperglycemia, mild cognitive impairment, omega fatty acids, polyphenols, unhealthy life style DOI: $10.1515 /$ jbcpp-2019-0105

Received: April 11, 2019; Accepted: October 25, 2019

\section{Introduction}

Cognition is the physiological process of acquiring and understanding the information received from sensing the environment and making judgment accordingly. Cognitive impairments affect the quality of life including social and professional activities [1]. Cognitive impairment associated with diabetes has been of serious concern to physicians worldwide. Diabetes mellitus, if not managed, may increase the risk of cognitive impairment and dementia [2]. Evidences suggest that type 2 diabetes increases the risk of progression of mild cognitive impairment (MCI) to dementia and Alzheimer's disease (AD) [3]. Although MCI may not cause difficulty in self-management activities in many patients, however, long-term cognitive dysfunctions or the progression of this condition may increase the risk of developing $\mathrm{AD}$ and affect cognitive system differentially [4]. MCI is the progressive step toward the occurrence of dementia and AD [5], [6], which can also be listed as one of the complications of diabetes [7]. Several studies have shown an association between diabetes and cognitive dysfunction, as the cognitive behavior deteriorates faster in diabetic patients [8], [9]. The cognitive behavior deteriorates faster in diabetic patients compared to non-diabetic elderly ones [10], [11]. A greater decline in cognitive function in diabetic patients ultimately affects the interconnecting pathways including insulin signaling, neuroinflammatory pathways, depression, and mitochondrial impairments [12]. The presence of cognitive dysfunction can further deteriorate the conditions like vision impairment, hearing loss, physical disabilities, and chronic pain, and difficulty in performing self-care [13]. The diabetic group performed significantly worse on 
memory functions, information-processing speed, attention, and executive functions and language comprehension [14]. Diabetic patients with MCI show greater decline in information processing speed than non-diabetic individuals [15], [16]. They possess lower levels of general intelligence [17] with loss of attention capacity [16]. These studies show a mechanistic link between the cognitive dysfunction, $\mathrm{AD}$, and type 2 diabetes. $\mathrm{AD}$ is the most common type of dementia that occurs in diabetic patients, followed by vascular dementia (VD), which is the second most common illness associated with this type of metabolic disease. In addition, type 2 diabetes can cause cerebrovascular disease leading to vascular cognitive impairment. Hippocampus and medial temporal lobe structures, responsible for the formation of new memories, showed histological atrophy in patients with MCI [18], [19]. Although the population-based studies have found the role of diabetes in the progression of $\mathrm{MCI}$, these studies failed to find an association between MCI and AD. A detailed insight on the mechanisms of cognition complication and periodic assessment of these conditions are recommended in all patients suffering from type 2 diabetes in order to develop effective strategies for prevention and treatment of the disease.

Unhealthy lifestyle is considered as the major contributor to diabetes and other health outcomes, causing a slow but progressive deterioration of mental health [20], [21]. People are more inclined toward cheap calories, engineered food, and increasingly adopting sedentary life resulting in cognitive decline, dementia, and AD [20], [22]. Inappropriate dietary habits and a sedentary lifestyle may promote increase in weight and obesity, which may lead to insulin resistance in people with type 2 diabetes [23]. Nutritional interventions are regarded as an effective alternative to protect against cognitive decline and neurodegeneration caused by diabetic conditions [24]. In this regard, the beneficial potential of dietary omega fatty acids (FAs) and flavonoids, found abundantly in fruit, vegetables, cocoa, and certain beverages, were the focus of research to prevent pathological mechanisms underlying cognitive and neurodegenerative diseases [25], [26]. A number of flavonoids derived from plants may prevent the age-related cognitive decline [26] and may restore the cholinergic neurotransmitter [27]. However, the molecular mechanism of action of flavonoids benefiting the patients with cognitive impairment has not been entirely elucidated [26]. The increased prevalence of cognitive decline in type 2 diabetes throughout the world and designing therapy for its prevention has serious challenges. More comprehensive clinical trials are needed to investigate whether interventions targeting the risk factors can reduce the risk of cognitive decline and dementia in diabetic patients. In this review, our aim is to highlight the risk factors such as age, hyperglycemia, high blood cholesterol, inflammation, and unhealthy lifestyle in cognitive impairment in type 2 diabetes patients and to give insight on nutritional intervention.

\section{Age, hyperglycemia, and $\mathrm{MCl}$}

The prevalence of cognitive impairments increases significantly with age of the individual. Age and certain Age was inversely related with performance on tasks for memory and information-processing speed in type 2 diabetic patients [14]. During aging, the increased oxidative stress, hyperglycemia or hypoglycemia, insulin resistance, and deposition of amyloid- $\beta$ protein in the brain are all the important risk factors for cognitive impairment [8]. Type 2 diabetes can accelerate age-related cognitive decline, making patients especially susceptible to cognitive impairment and dementia. Such patients may have reduced performance on numerous domains of cognitive function. The increased vulnerability of cognitive impairments and dementia with age was correlated with early life stress that alters brain structure and functions [28]. Hyperglycemia was suggested as the strongest risk factor for developing cognitive impairment [29]. Individuals with chronic hyperglycemia accelerate the production of advanced glycation end-products (AGEs) that accumulate in the blood and tissues [30]. The formation of AGEs takes place by the Maillard reaction. In this reaction, the glucose reacts non-enzymatically with the amino group of proteins with the resultant production of a Schiff base that rearranges into Amadori compounds [31]. The AGEs are made by very slow irreversible dehydration and condensation reactions of these Amadori adducts. Hyperglycemia-mediated AGE production, together with oxidative stress, was regarded as the factor that can degenerate neurons and damage vascular endothelium leading to impairment in cognitive function [32]. Recent evidence showed a direct association between the accumulation of AGEs and development of diabetic vascular complications [33]. Even in non-diabetic individuals the impaired glucose tolerance poses a critical risk factor for cognitive dysfunction [8]. Such patients with impaired glucose tolerance exhibit lower mini-mental status examination (MMSE) [34] and increased incidence of AD [35] in comparison to individuals with normal glucose tolerance. However, the pathophysiology of this relationship is unclear, and more work is required to identify the impact of hyperglycemia on the risk of cognitive impairments. 


\section{Hypercholesterolemia, inflammation, and $\mathrm{MCl}$}

Hypercholesterolemia and hypertriglyceridemia were associated with the increased risk for AD [36]. However, the impact of hypercholesterolemia and other lipid disorders noted in patients with type 2 diabetes on AD pathogenesis is less known. Human studies relating hypertriglyceridemia to AD are not sufficient to provide concluding evidence, while animal studies suggest that high plasma triglyceride levels may lead to deposition of $\beta$ amyloid in mouse models of AD [37]. Diabetic patients with advanced age and hyperlipidemia were at increased risk of transitioning to $\mathrm{AD}$ [38]. Other studies reported that elevated lipid profiles do not contribute to decline in cognitive behavior [39]. It is unclear if the hyperlipidemia in diabetic patients contributes to cognitive decline or having risk of developing AD. Thus, further clinical studies on the impact of hyperlipidemia or hypercholesterolemia on the risks of cognitive impairments and AD in diabetic subjects needed to elucidate the role and mechanism by which these factors contribute to the progression of neuropathology.

The various pathological conditions in diabetic patients may cause elevated levels of pro-inflammatory cytokines in the specific regions of the brain. These pro-inflammatory mediators are responsible for severe inflammation in brain tissue that affects the synaptic plasticity and, thus, long-term memory [40]. Several studies showed that high-fat diet and consumption of high amounts of carbohydrate may induce cognitive deteriorations accompanied by an increase in neuroinflammatory markers in the hippocampus region of the brain [41]. Short-term duration and chronic high-fat-diet (HFD) feeding was shown to cause cognitive impairment and neuroinflammation in mice [42]. The reduction in inflammatory markers, thus, may provide therapeutic potential in the treatment of diseases associated with neuroinflammation. However, very few studies were performed on the alleviation of cognition deficits by protecting neurons from inflammation injury in diabetic subjects.

\section{Unhealthy lifestyle and $\mathrm{MCl}$}

Lifestyle diseases occur in people primarily because of their inappropriate daily habits and inappropriate relationship with their environment. Remarkable changes in lifestyles combined with age and diabetes increase the prevalence of cognition decline [43]. The severity of diabetes reflects the risk of MCI, thus, a poor lifestyle can be regarded as the major risk factor for MCI as well as diabetes [44]. The risk factors for younger adults will vary from older adults as the older people will have multiple chronic conditions that may increase the risk of MCI [45]. Thus, preventive strategies for younger adults will vary from those of the older adults. In older adults, the preventive therapy for MCI may need to begin in midlife and continue until appearance of symptoms. A number of studies were suggested for the possible link between type 2 diabetes and cognitive impairment with lifestyle of the people [22], [20]. Poor dietary habits and obesity can lead to an increase in cognitive and mood dysfunctions, suggesting a strong association between the diet and disease [46]. The molecular mechanism describing how consuming HFD can lead to cognitive impairments was reviewed [47]. These authors and others showed that HFD and obesity cause systemic inflammation that leads to inflammation in the hypothalamus region of the brain [48]. Excess circulating free FAs reach the brain and lead to increased expression of innate immune cytokines. The free FAs and cytokines initiate local inflammation in the specific regions of the brain, including microglial proliferation [47]. Other studies also demonstrated that short-term consumption of high saturated fat and/or high sugar, triggers neuroinflammatory processes [41], [49]. Activated microglia within the brain structures may initiate the production of pro-inflammatory molecules such as interleukin- $1 \beta$ (IL1 $\beta)$, IL-6, and tumor necrosis factor- $\alpha$ (TNF- $\alpha$ ). These pro-inflammatory molecules can sensitize and damage neurons, thus affecting both the cognition (hippocampus) and emotion (hypothalamus, amygdala, prefrontal cortex, and others) abilities of individuals. Consequently, the inflammation-induced synaptic dysfunction and neurodegeneration within the brain regions result in the loss of cognitive function leading to memory impairments and/or depression-like behaviors.

Barnes and Joyner [50] showed that unhealthy diet is associated with lower cognitive scores [50]. There is a close link between the physical inactivity and cognitive decline leading to the progression for dementia [51]. The incidence of MCI in diabetic patients having a poor lifestyle is several times higher than the nondiabetic patients. Thus, by improving the lifestyle, the risk and the progression of $\mathrm{MCI}$ can be prevented in diabetic patients. A study by Yomamoto et al. [52] suggested that lifestyle intervention has a beneficial effect on cognitive decline in elderly people with type 2 diabetes [52]. Another study by Hu et al. [53] supports the hypothesis that the majority of cases of type 2 diabetes could be prevented by the adoption of a healthier lifestyle [53]. The study also suggests that overweight or obesity was the single most important predictor of diabetes and unhealthy lifestyle associated with a significantly increased risk of diabetes, even after adjustment for the 
body mass index [53]. These data not only show the correlation of MCI with diabetes but also that the risk of MCI with the possibility of dementia is greater in the diabetic patients having an unhealthy lifestyle.

\section{Possible intervention strategies to improve cognitive function}

The alterations in synaptic transmission and plasticity that occur during the pathogenesis of disease or normal aging process are the chief causes of the decline of cognitive functions [54], [55]. Thus, the treatment strategies for the prevention of cognitive decline during aging or diseases should involve the modulation of synaptic function and neuronal survival. Lifestyle interventions consisting of physical exercise and calorie-restricted diets and consumption of healthy fruits and vegetables led to a lowered incidence rate of cognition decline [46]. Healthy nutrients and foods such as functional foods may have potential health benefits in individuals with MCI. The use of functional foods in the prevention and management of diseases steadily increased over the past few decades. The functional foods derived from vegetables, cereals, and fruits may act as promising therapeutic agents. Such foods consist of polyphenols, terpenoids, flavonoids, alkaloids, sterols, pigments, and unsaturated FAs that play an important role in maintaining wellness and contribute to preventing cancer, depression, obesity, asthma, and cognitive decline [56], [57]. These foods act by various modes in the cells chiefly by enhancing antioxidant activity, anti-inflammatory, cellular signaling, improved insulin sensitivity, and reduced resistance [58]. Among the functional foods, the dietary omega FAs and flavonoids comprised the greater part in the management of cognitive impairment.

\section{Omega fatty acids}

Dietary consumption of foods rich in omega FAs may help in improving the cognitive functions of the brain. Arachidonic acid (AA, 20:4 omega-6) and docosahexaenoic acid (DHA, 22:6 omega-3) are the main omega- 6 and omega-3 long-chain polyunsaturated FAs (PUFA) synthesized in the brain from linolenic acid (LA, 18:2 omega6) and $\alpha$-linolenic acid (ALA, 18:3 omega-3), respectively. Both omega- 6 and omega-3 regulate fundamental neurobiological processes that are involved in cognition and mood [59], [60]. As the brain possesses limited capacity to synthesize long-chain PUFA, therefore, dietary supplement and increased consumption of DHA-rich products may be beneficial in improving cognitive functions. Omega-3 and omega-6 FAs are found in green vegetables, seeds and nuts, coconut, palm, flax, and walnuts. The regulatory roles of DHA and AA in the modulation of neurotransmission and neuroinflammation, as key processes in cognition and mood, were recently reported [60]. Omega-3 FA reduces inflammation, regulates neurogenesis, and counters damage caused by oxve stress, thus aiding in neuroprotection [61], [62]. Supplementation of omega-3 FAs caused improvement in cognitive performance in rats [63] and improved adult's episodic memory that had mild memory problems [64]. Although most of the studies on the effect of omega 3 FAs on the performance of cognitive functions were conducted using animal models [63], only a few epidemiological studies are reported in humans for the beneficial effects of omega $3 \mathrm{FAs}$ on age-related improvement in cognitive functions [65], [66]. In a human intervention trial study involving patients with mild memory complaints, DHA/EPA-rich fish oil was supplemented at a dose of $1.75 \mathrm{~g}$ [67]. These studies reported the advantageous effect of supplementation of fish oil in stopping the progression of $\mathrm{AD}$ in an age group of $>60$. However, the effects of DHA/EPA in ameliorating the MCI in older people remain to be established. The supplementation of $240 \mathrm{mg} /$ day of AA and DHA, or $240 \mathrm{mg} /$ day of olive oil, respectively, to human amnesic patients with MCI showed a considerable improvement in the immediate memory and attention score [68]. To date, the effective dose that can be used safely to ameliorate the decline in MCI by patients with diabetes was not worked out [69]. Thus, a more comprehensive study addressing the dose at which omega FAs improves or protects the cognitive function in type 2 diabetes may be planned in the future.

\section{Polyphenols}

Polyphenols are naturally occurring secondary metabolites of plants widely distributed in tea, wines, vegetables, fruits, and cereals and are the most important part of the human diet. Foods rich in polyphenolic compounds were shown to exert benefit in the prevention of the age-related cognitive decline [70]. In most of the cases, type 2 diabetes and cognitive impairments are associated with inflammation and oxidative stress; therefore, strategies should be oriented toward the reduction of oxidative stress and toward the reduction of vulnerability to damage by inflammatory mediators. Many colorful fruits and vegetables are rich source of polyphenolic compounds that have potent antioxidant and anti-inflammatory activities [71]. Preclinical studies in humans 
confirm the reduction of neuroinflammation and oxidative stress in the brain of those individuals who have taken a diet rich in polyphenolic-rich foods.

Flavonoids encompass the most important group of polyphenols with protective properties against neurodegenerative [72], [73] and cardiovascular diseases [74], [75]. Flavonoids are represented by six major subclasses: flavonols, flavones, flavanones, flavanols, anthocyanins, and isoflavones. The number and arrangement of the hydroxyl groups in their ring and their extent of alkylation and/or glycosylation make individual differences within each group. Flavonoids are universally found in fruits, vegetables, cereals, teas, and wines, and their intake protects individuals against many diseases including cognitive decline during aging [70] (Table 1).

Table 1: List of flavonoid, their classes, and sources that help in improving the cognitive functions.

\begin{tabular}{|c|c|c|c|c|}
\hline $\begin{array}{l}\text { S. } \\
\text { no. }\end{array}$ & $\begin{array}{l}\text { Name of flavonoids } \\
\text { with benefit in } \\
\text { cognitive functions }\end{array}$ & Class & Source & References \\
\hline 1. & Quercetin & Flavonols & $\begin{array}{l}\text { Apples, honey, raspberries, onions, red grapes, } \\
\text { cherries, citrus fruits, and vegetables }\end{array}$ & $\begin{array}{r}\text { [76], [77], [78], } \\
{[79],[80]}\end{array}$ \\
\hline 2. & Rutin & Flavonols & $\begin{array}{l}\text { Buckwheat, apricots, cherries, plum, oranges, green } \\
\text { tea, grape seeds, red pepper, apple, citrus fruits, } \\
\text { berries }\end{array}$ & [81], [82], [83] \\
\hline 3. & $\begin{array}{l}\text { Kaempferol } \\
\text { 3-O- } \beta \text {-D-galactoside }\end{array}$ & Flavonols & $\begin{array}{l}\text { Apples, grapes, tomatoes, green tea, potatoes, } \\
\text { onions, broccoli, Brussels sprouts, squash, } \\
\text { cucumbers, lettuce, green beans, peaches, } \\
\text { blackberries, raspberries, spinach }\end{array}$ & [84], [85], [86] \\
\hline 4. & Macluraxanthone & Xanthones & Maclura tinctoria (hedge apple), Dyer's mulberry & [87] \\
\hline 5. & Baicalein & Flavones & Roots of Scutellaria baicalensis & [88] \\
\hline 6. & Tiliroside & $\begin{array}{l}\text { Glycosidic } \\
\text { flavonoid }\end{array}$ & Strawberry, raspberry, rose hips & [89] \\
\hline 7. & Apigenin & Flavones & $\begin{array}{l}\text { Fruits and vegetables, including parsley, onions, } \\
\text { oranges, tea, chamomile, wheat sprouts, milk, } \\
\text { chocolate, commercial, reduced fat }\end{array}$ & [77] \\
\hline 8. & Biochanin A, & Isoflavone & $\begin{array}{l}\text { Red clover, soya, alfalfa sprouts, peanuts, chickpeas } \\
\text { (Cicer arietinum), other legumes }\end{array}$ & [90] \\
\hline 9. & Naringenin & Flavanone & $\begin{array}{l}\text { Citrus, cherries, grapefruit, and cocoa, tomatoes } \\
\text { skin }\end{array}$ & [91], [92] \\
\hline 10. & Genistein, & Isoflavone & $\begin{array}{l}\text { Fats, oils, beef, red clover, soyabeans, psoralea, } \\
\text { lupin, fava beans }\end{array}$ & $\begin{array}{r}{[93],[94],[95],} \\
{[96]}\end{array}$ \\
\hline 11. & $\begin{array}{l}\text { Luteolin-7-O- } \\
\text { rutinoside, }\end{array}$ & Flavones & $\begin{array}{l}\text { Celery, broccoli, green pepper, parsley, thyme, } \\
\text { dandelion, perilla, chamomile tea, carrots, olive oil, } \\
\text { peppermint, rosemary, navel oranges }\end{array}$ & [97], [98] \\
\hline 12. & Diosmin & Flavone & Vetch & [99] \\
\hline 13. & Silibinin & Flavanone & Milk thistle plant (Silybum marianum) & [100] \\
\hline 14. & Rhamnetin & $\begin{array}{l}\text { Flavonol } \\
\text { derivatives }\end{array}$ & $\begin{array}{l}\text { Cloves, sweet wormwood, and green vegetables } \\
\text { such as coriander leaves and seeds, cloves, and } \\
\text { coriander }\end{array}$ & [101] \\
\hline 15. & Isorhamnetin & $\begin{array}{l}\text { Flavonol } \\
\text { derivatives }\end{array}$ & Yellow or red onions, spices & [102] \\
\hline 16. & Rhamnazin & $\begin{array}{l}\text { Flavonol } \\
\text { derivatives }\end{array}$ & Rhamnus petiolaris (buckthorn plant) & [27], [103] \\
\hline
\end{tabular}

After entering into the gastrointestinal tract, the flavonoids are metabolized by interacting with several enzymes to their respective metabolites, which go into the bloodstream. Flavonoids or their metabolites may cross the blood-brain barrier and, thus, reach the brain tissue [104]. In human studies involving 50- to 69-year-old healthy subjects, the intake of a diet rich in cocoa flavanol was shown to enhance the cognitive abilities [105]. In a double-blind crossover study of 30 young adults between age groups, 18-35 were given $520 \mathrm{mg}$ of cocoa flavonol [106]. At this dose, significant improvements in working memory were obtained relative to the control. The main flavanol constituent found in green tea is the epigallocatechin gallate (EGCG). In a double-blind, placebo-controlled crossover study, green tea, $135 \mathrm{mg}$ and $270 \mathrm{mg}$ doses of EGCG extract were administered. However, at these doses, no beneficial effect on cognitive function was noted [107]. Age-related motor and cognitive deficits were significantly reversed by extracts of blueberry or strawberry [108]. The polyphenols present in berry fruits have many actions in cells including reducing inflammation and oxidative stress by their antiinflammatory and antioxidant activities [109]. Blueberry supplementation rich in anthocyanidins has shown to improve cognitive function in healthy older adults [110] suggesting that regular dietary consumption of berry 
fruit may be an effective strategy to prevent cognitive dysfunction. In a small crossover study with 14 children, the supplementation of fresh whole blueberries ( $200 \mathrm{~g}, 143 \mathrm{mg}$ anthocyanins) for $2 \mathrm{~h}$ produced no effects on executive function tasks; however, an improvement in delayed word recall after was found [111]. In a doubleblind, placebo-controlled, crossover study, the effects of blueberry doses (127 mg and $253 \mathrm{mg}$ anthocyanins) on cognitive functions in children were investigated [112]. Their results showed that blueberry in the highest dose (253 mg anthocyanins) improved immediate word recall after $1.25 \mathrm{~h}$. The molecular mechanism of the principal bioactive component found in blueberry was worked out. The blueberry extracts were found to decrease nuclear factor- $\kappa \mathrm{B}$ (NF- $\kappa \mathrm{B}$ ) in the brain levels in aged rats compared to the controls [113] suggesting that flavonoids exert their protective actions through cellular signaling pathways especially on the NF- $\kappa$ B activity [114]. Strawberries exhibit antioxidant and anti-inflammatory activities that protect the brain from neurochemical and behavioral alterations. It improves the memory processes in aged rats [108] and prevents the effects of aging on neuronal signal transduction [115]. Grape juice consumption was shown to improve the memory performance in older humans [116]. The extracts of the berries are enriched in polyphenols, in particular, in flavanols, anthocyanins, and resveratrol. The effects of cherry flavonoids ( $300 \mathrm{~mL}$ cherry juice contains $55 \mathrm{mg}$ anthocyanins) on the improvements of MCI were analyzed in younger, older adults, and older adults with MCI. After $6 \mathrm{~h}$ of supplementation, the task switching function was improved in older adults [117]. Orange juice prepared by adding flavanone-rich orange pulp to get the desired total flavonoid content $(272 \mathrm{mg} ; 220.46 \mathrm{mg}$ hesperidin, $34.54 \mathrm{mg}$ narirutin) when supplemented to middle aged adults showed improvement in psychomotor performance after

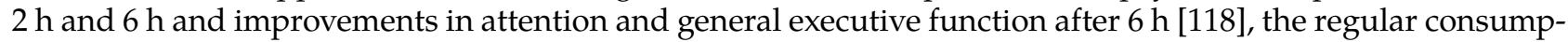
tion of which facilitates the identification of their functional and behavioral effects. Blackberry and mulberry supplementation to aged rats [119] and in senescence-accelerated mice [120] improved age-related memory deficits. These studies show that adequate consumption of flavonoid/polyphenol-rich fruits and vegetables was found to be associated with the prevention of cognitive decline in humans [121], [122].

\section{Mechanism of action of flavonoids}

The mechanism of action of flavonoids in neuronal cells was not well illustrated. Flavonoids or their metabolites, upon reaching the brain, may bind to several receptors including $\gamma$-aminobutyric acid type A receptor (GABAA), nicotinic cholinergic receptors, adenosine receptors, estrogen, and testosterone receptors [123]. However, due to inadequate understanding on their metabolism and mechanism of action on neuronal cells, flavonoids have not yet been effectively used in therapy to cure brain-related disorders. To fully explore the usefulness of these natural compounds for the treatment of nervous system-related disorders, a critical knowledge of the molecular mechanisms of action is important. The major mechanisms of action of flavonoids on improving cognitive through their (i) anti-inflammatory, (ii) antioxidant, or (iii) signaling actions. Their beneficial effect largely depends on their bioavailability in tissues or cells and preventive action against inflammation and oxidative stress. Once consumed, the flavonoids are efficiently metabolized in the body before being able to exert their beneficial effects [124]. Activating cellular signaling pathway is one of the important mechanisms of flavonoid action in neuroprotection and strengthening synaptic plasticity. Another mechanism of action of flavonoids on neuronal tissues is their ability to modulate the expression of specific genes and interaction with metabolic enzymes, and thus impacting mitochondrial activity [125]. 


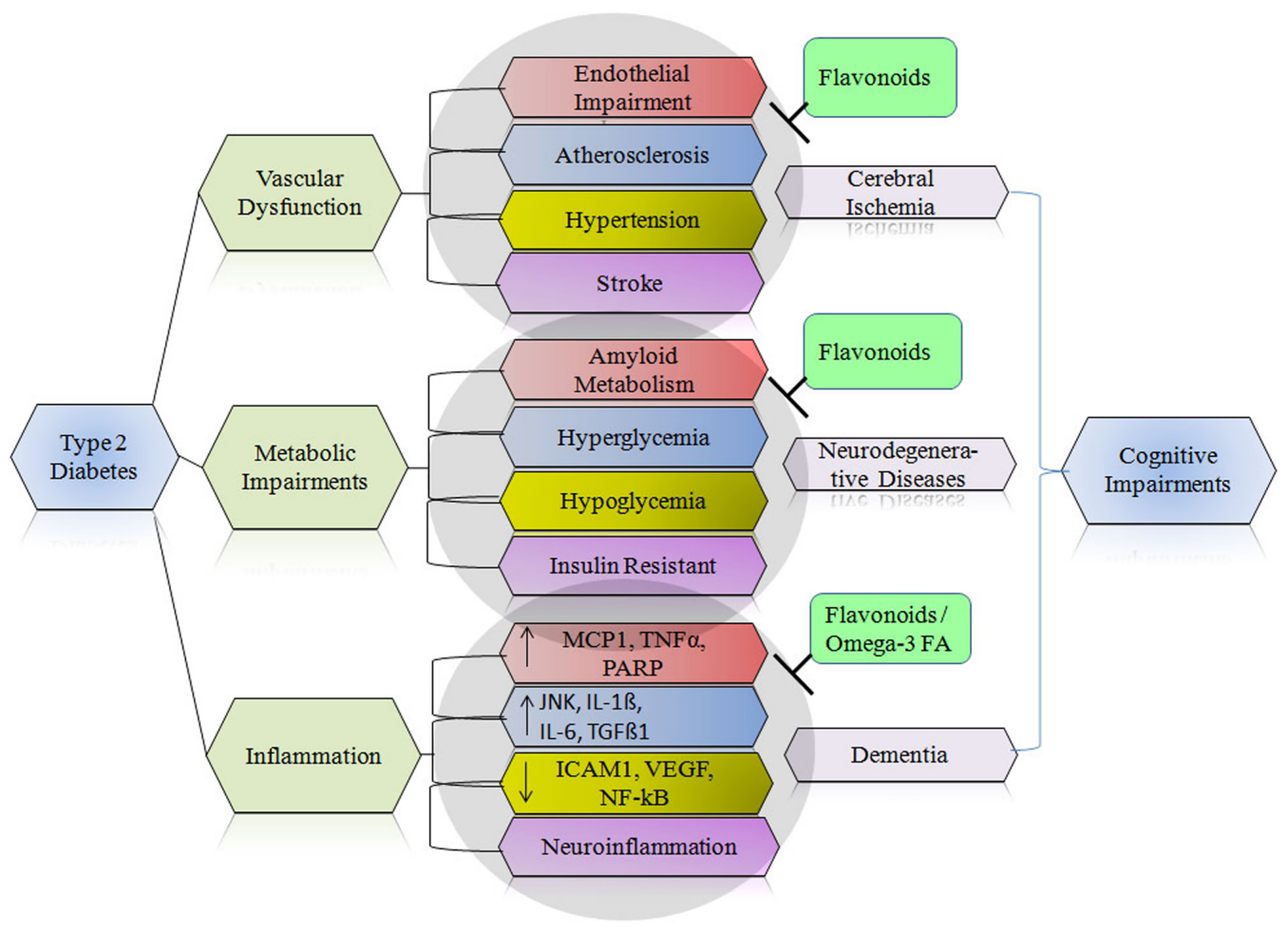

Figure 1: Schematic representation of the mechanisms of action of flavonoids in improving cognitive functions in type 2 diabetes.

Type 2 diabetes patients exhibit impaired vascular and metabolic functions accompanied by an increased inflammatory state. Salient aspects of vascular impairments include endothelial impairments, atherosclerosis, hypertension, and stroke. The metabolic impairments impact amyloid metabolism, hyperglycemia, hypoglycemia, and insulin resistance. Diabetesinduced inflammatory mechanism may cause vascular impairments and increase neuroinflammation by upregulating monocyte chemoattractant protein 1 (MCP1), TNF- $\alpha$, poly ADP ribose polymerase (PARP), JNK, IL-1 $\beta$, interleukin 6 (IL6 ), and transforming growth factor- $\beta 1$ (TGF $\beta 1$ ) and downregulating intercellular adhesion molecule 1 (ICAM- 1 ), vascular endothelial growth factor (VEGF), and NF-kB. These changes may cause impairments in cognitive function by various lesions such as cerebral ischemia, dementia, and neurodegenerative diseases. The dietary omega-3 fatty acids (FAs) and flavonoids improve cognition functions by their potential to protect neurons from inflammation, potential to protect metabolic impairments, and promote neurons against vascular dysfunctions. These protective effects of flavonoids are underpinned by neuronal signaling cascades, antioxidative properties, and anti-inflammatory potential.

\section{Anti-inflammatory effects}

Continuous inflammation in the nervous system was regarded as the major cause of neurodegeneration occurring in AD and Parkinson's disease. Increased activation of microglial cells during neuroinflammation causes toxic reactive oxygen species generation. Flavonoids exert its anti-neuroinflammatory action via several mechanisms including inhibiting the inflammatory cytokines TNF- $\alpha$ and interleukin $1 \beta$ (IL-1 $\beta$ ) by reducing microglial activation; inhibiting nitric oxide production by downregulation of iNOS activity; and reducing ROS generation by activated glia cells by suppressing the activation of NADPH oxidase and downregulating NF- $\kappa$ B pro-inflammatory transcription factor [26], [126]. Different flavonoids target different anti-inflammatory mechanisms for protecting the brain cells. Flavonoids, found in green tea, such as epicatechin and catechin, inhibit TNF- $\alpha$ release but do not prevent nitric oxide production [127]. People who are consuming flavonoid-rich diet have reduced levels of inflammatory markers such as C-reactive protein (CRP) and interlukin-6 (IL-6) [128]. Dietary intake of anthocyanidins and isoflavones including blueberry anthocyanin lowers the blood levels of CRP [129] and pro-inflammatory cytokines and chemokines [130].

\section{Antioxidant effects}

Oxidative stress during inflammation is the result of increased production of ROS such as superoxide anion, hydrogen peroxide $\left(\mathrm{H}_{2} \mathrm{O}_{2}\right)$, and hydroxyl radicals $\left(\mathrm{HO}^{\bullet}\right)$ via the $\mathrm{NAD}(\mathrm{P}) \mathrm{H}$ and mitochondrial electron transport chain mechanisms [131], [132]. These ROS are produced in a natural course by the metabolism of energy sub- 
strates. Energy substrates in the form of glucose or FAs when present in excess enter the Krebs cycle and produce excess mitochondrial NADH that is consequently converted to ROS [133]. Some amount of oxidative damage takes place during normal metabolism of food substrates, and the endogenous antioxidative defense system tries to repair and attenuate the damage. However, if not neutralized, the increased ROS production leads to intensive oxidative damage to neuronal tissues. Oxidative tissue damage was found to be associated with aging and age-associated cognitive decline. Dietary polyphenols including flavonoids have the capacity to diminish age-associated cognitive deficit and restore cellular damage due to their ability to activate the antioxidant defense system in the cells. Many fruits and vegetables contain an abundant amount of dietary antioxidants, and therefore, consumption of adequate amounts of such fruits and vegetables protect against oxidative damage. During senescence, a link was established between the antioxidant status and cognitive functions [134], and the dietary fruits and vegetables are the mostly important natural source with antioxidant potential. High dietary consumption of specific polyphenols may help to preserve verbal memory during brain aging. These polyphenols can cross the blood-brain barrier and mediate neuroprotection from a variety of ailments. Resveratrol, a polyphenol found in red wine, shows potential antioxidant activity in several CNS disorders, experimental cerebral ischemia, Parkinson disease, amyotrophic lateral sclerosis, cognitive impairments, and aging [135]. Certain vitamins such as vitamins B, E, and C and omega FAs $(\omega-3 / \omega-6)$ and polyphenols can prevent cognitive decline [136]. Polyphenols, due to the presence of benzene ring-bound hydroxyl groups, have extensive antioxidative activity of quenching ROS [137]. Some polyphenols inhibit the major ROS-forming enzymes including monoamine oxidase or xanthine oxidase directly [137], whereas others reduce ROS by chelating iron and copper ions rendering them inactive to participate in free radical-generating reactions [138] that can prevent neurotoxicity and cognitive decline. Some polyphenols are able to modulate the activity of sirtuins, thus, regulating mitochondrial biogenesis [139], mitochondrial membrane potential, and mitochondrial production of ROS. Through modulation of signaling cascades including Nrf2 and NF- $k B$, some flavonoids induce the expression of the antioxidant and detoxifying enzymes in the cells, thus, increasing chances of cell survival [140]. Understanding of the dynamic beneficial effects of these dietary substances may play a role in designing therapy in improving cognitive function thus reducing the risk associated with aging and neurodegenerative disorders.

\section{Cellular signaling molecules}

The cognitive functioning requires tight regulation of neuronal growth and synaptic metabolism. At a gene level, the polyphenols interact with neuronal and glial signaling pathways that affect gene expression and interfere with programmed cell death [141]. Signaling pathways involved during the inflammation in most cases increase IL-1 and tumor necrosis factor (TNF- $\alpha$ ) receptor families in cells (Figure 1). Activation of these receptors cause the activation of mitogen-activated protein kinases (MAPK) such as extracellular response kinases (ERK 1/2), jun N-terminal kinase (JNK), p38 MAPK, and inhibitor of nuclear factor $\kappa B$ kinases (IKK). These signaling proteins are involved in the activation of transcription factors such as activation protein (AP-1) and cAMP response element-binding proteins that promote expression of pro-inflammatory genes [142]. Interaction of flavonoids with the extracellular signal-regulated kinase (ERK) pathway protects neuronal tissues from apoptosis [72]. The glycosidic flavanone, hesperidin, was found to stimulate the differentiation of progenitor cells in brain in vitro and prevent cell death via the MAPK and PI3K pathway activation pathway [143]. Through the inhibition of NF- $\mathrm{kB}$ and MAPK phosphorylation, the 0.2 to $1 \mu \mathrm{M}$ concentration of $4^{\prime}$-O-methyl (-)-epicatechin and its glucuronide and EC-4'-O-sulfate caused the attenuation of the adhesion of monocytes to endothelial cells [144]. Quercetin was shown to bind with PI3K and inhibits the AP-1 and suppression of NF$\kappa \mathrm{B}$ activation [145]. This flavonoid was found to protect $\beta$ cells from the damage induced by cytokines [146]. Citrus flavanone, hesperetin was found to activate ERK1/2 in cortical neurons, which subsequently leads to the activation of the CREB transcription factor. In brain, the activation of CREB is considered important in supporting the synaptic plasticity [147] and protecting neuronal survival. Studies showed that flavanol (-) epicatechin exerts its signaling by increasing the expression of the AMPA receptor (AMPAR) GluR2 subunit and initiates CREB phosphorylation [148]. Flavanone found in citrus fruits activate the Akt/PKB pathway and subsequently inhibits apoptosis by inactivation of apoptosis signal-regulating kinase 1 (ASK1), Bad, caspase-9 and caspase-3 [149]. These data suggest that flavonoids protect neuronal tissue against toxicants, aging, etc., by activating the cell signaling survival pathway.

Polyphenols have pronounced positive impact on nitric oxide signaling mediating various cell functions. While the normal production of NO is associated with cell signaling, its overproduction is associated with an increase in inducible NOS (iNOS) stimulation, which is toxic to cells. Polyphenols also positively influence NO signaling via brain-derived neurotrophic factor (BDNF) in regulation of neuronal survival and differentiation [150]. The inhibition of endothelial nitric oxide synthase (eNOS) was found to be associated with the cognitive decline especially spatial learning deficits [151]. The inhibition of eNOS was shown to reduce the flow of 
blood to the brain, which was suggested to contribute to cognitive decline [152]. Flavonol and flavone classes of flavonoids such as quercetin and luteolin, respectively, were found to activate eNOS [153]. Experiments in an animal model also showed that modulation of NO levels via regulated expression of NOS may protect against aging, memory loss, and as well as cognitive tasks relating to learning and memory [154]. Thus, the ability of flavonoids to upregulate the eNOS and downregulate the iNOS must be utilized to protect the cognitive function. Clinical trials and human studies on the usefulness of polyphenols in maintaining the homeostasis of cognitive and memory functions during various neurodegenerative diseases are still at the incipient stage. Similarly, the quest for exploring the question of the beneficial effect of flavonoids in relation to the improving behavioral functions in individuals of different age groups is still going on.

\section{Conclusions}

Diabetes and associated cognitive impairment greatly affect the quality of life in all age groups. Diabetic patients reduced their capacity to defend against the oxidative stress and show increased activation of inflammatory pathways in cells. The increased burden of oxidative stress and increased inflammation in the body put people at increased risk for cognition dysfunction and neurodegeneration. The occurrence of cognitive impairment and changes in behavior significantly decreases the quality of life of diabetic patients. Proper dietary management can prevent occurrence of $\mathrm{MCI}$ in type 2 diabetes patients, thus improving the quality of life. The correct diagnosis of cognitive impairments during the initial phase of the disease can be helpful in timely treatment. Thus, there is an urgent need of understanding the pathophysiology of the disorder and to identify molecular targets and pathways that might lead to improved therapy in the future. Based on the studies and our observations, it can be concluded that an unhealthy lifestyle, such as improper diet and physical inactivity, may be the major risk factors for MCI especially in diabetic patients. The therapeutic medicine for the treatment of such disorders was a much-discussed problem in recent years. Natural products derived from plants such as polyphenols, especially flavonoids, found in berries or other dark-colored fruits and vegetables, may protect brain cells against the damaging effects of oxidative stress and neuro-inflammation, thus protecting against cognitive dysfunctions. Almost all flavonoids undergo extensive modifications and bioconversion into various metabolites once they reach the alimentary tract. Therefore, further understanding of the mechanism of bioconversion of flavonoids and concentration of metabolites at which they provide benefits for improving cognitive function is essential.

\section{Future directions}

Ongoing description clearly indicates that the exact cause of MCI in type 2 diabetes is not well known. The risk factors for MCI in such patients were not studied extensively. The healthy lifestyle response relationships with MCI outcomes are lacking. Comparison of different physical exercises on the amelioration of cognitive impairments was not conducted. Therefore, more comprehensive epidemiological studies of all age groups and treatment that relieve the symptoms of MCI in diabetic patients need to be initiated. The important questions highly relevant to the clinical problem associated with cognitive decline in type 2 diabetes include: 1) What are the factors that influence the individual metabolic or environmental stress leading to MCI in diabetic patients? and 2) What are the lapses that cause hindrance to clinicians to manage the disease even before the appearance of behavioral symptoms? Future researches may be focused on 1) the identification of unhealthy lifestyle risks associated with MCI in diabetic patients, 2) correlation of MCI with vascular diseases, stroke, heart diseases, hypertension, etc., and 3) formulating effective motivational interventions to adopt the awareness on healthy lifestyles among people. In addition, how the unhealthy lifestyle and stress mediators affect the synapses and neurons in a specific region of the brain in MCI needs to be explored. Prescribing the bioactive components with knowledge of dose, duration, and bioavailability in tissues especially in different regions of the brain are some of the critical issues that need to be addressed in the future. It is recommended to clinicians to diagnose the early symptoms of MCI and start prevention and treatment approaches at the earliest signs of clinical diagnosis.

\section{Acknowledgments}

The authors thanks all study participants for their involvement. 
Research funding: Financial support was provided by the research grant received from Vikram University Ujjain (Science grant Zoo 2017) and MP Council of Science and Technology (Biotechnology facility grant), Bhopal, India.

Author contributions: It is certified that all authors have read and approved the final manuscript and included details of the author's contributions to the manuscript. The authors' contributions are as follows: Garima Sharma, Arti Parihar, and Mordhwaj Parihar were the principal investigators responsible for the design, execution of the present study, and writing of the article; Tanay Talaiya contributed to the editing of the article; and Kirti Dubey and Bhagyesh Porwal contributed in revising the manuscript. All authors read and contributed to the finalization of the manuscript.

Competing interests: Authors, Garima Sharma, Arti Parihar, Tanay Talaiya, Kirti Dubey, Bhagyesh Porwal, and Mordhwaj S Parihar have no conflict of interests.

\section{References}

[1] Millan M], Agid Y, Brune M, Bullmore ET, Carter CS, Clayton NS, et al. Cognitive dysfunction in psychiatric disorders: characteristics, causes and the quest for improved therapy. Nat Rev Drug Discov 2012;11:141-68.

[2] Johnston H, McCrimmon R, Petrie ], Astell A. An estimate of lifetime cognitive change and its relationship with diabetes health in older adults with type 1 diabetes: preliminary results. Behav Neurol 2010;23:165-7.

[3] Biessels G], Strachan MW, Visseren FL, Kappelle L], Whitmer RA. Dementia and cognitive decline in type 2 diabetes and prediabetic stages: towards targeted interventions. Lancet Diabetes Endocrinol 2014;2:246-55.

[4] Arvanitakis Z, Wilson RS, Bienias ]L, Evans DA, Bennett DA. Diabetes mellitus and risk of Alzheimer disease and decline in cognitive function. Arch Neurol 2004;61:661-6.

[5] Petersen RC, Smith CE, Waring SC, Ivnik R], Tangalos EG, Kokmen E. Mild cognitive impairment: clinical characterization and outcome. Arch Neurol 1999;56:303-8.

[6] Kawamura T, Umemura T, Hotta N. Cognitive impairment in diabetic patients: can diabetic control prevent cognitive decline?] Diabetes Investig 2012;3:413-23.

[7] Mallorqui-Bague N, Lozano-Madrid M, Toledo E, Corella D, Salas-Salvadó ], Cuenca-Royo A, et al. Type 2 diabetes and cognitive impairment in an older population with overweight or obesity and metabolic syndrome: baseline cross-sectional analysis of the PREDIMEDplus study. Sci Rep 2018;8:16128.

[8] Kodl CT, Seaquist ER. Cognitive dysfunction and diabetes mellitus. Endocr Rev 2008;29:494-511.

[9] Takeda S, Sato N, Uchio-Yamada K, Sawada K, Kunieda T, Takeuchi D, et al. Diabetes-accelerated memory dysfunction via cerebrovascular inflammation and Abeta deposition in an Alzheimer mouse model with diabetes. Proc Natl Acad Sci USA 2010;107:7036-41.

[10] Ravona-Springer R, Luo X, Schmeidler ], Wysocki M, Lesser G, Rapp M, et al. Diabetes is associated with increased rate of cognitive decline in questionably demented elderly. Dement Ceriatr Cogn Disord 2010;29:68-74.

[11] Biessels C], Deary I], Ryan CM. Cognition and diabetes: a lifespan perspective. Lancet Neurol 2008;7:184-90.

[12] Sullivan MD, Katon W], Lovato LC, Miller ME, Murray AM, Horowitz KR, et al. Association of depression with accelerated cognitive decline among patients with type 2 diabetes in the ACCORD-MIND. trial. JAMA Psychiatry 2013;70:1041-7.

[13] Munshi MN. Cognitive dysfunction in older adults with diabetes: what a clinician needs to know. Diabetes Care 2017;40:461-7.

[14] Ruis C, Biessels C], Gorter K], Van den Donk M, Kappelle L], Rutten GE. Cognition in the early stage of type 2 diabetes. Diabetes Care 2009;32:1261-5.

[15] Ryan CM, Geckle MO, Orchard T]. Cognitive efficiency declines over time in adults with Type 1 diabetes: effects of micro- and macrovascular complications. Diabetologia 2003;46:940-8.

[16] Wessels AM, Rombouts SA, Remijnse PL, Boom Y, Scheltens P, Barkhof F, et al. Cognitive performance in type 1 diabetes patients is associated with cerebral white matter volume. Diabetologia 2007;50:1763-9.

[17] Northam E, Anderson P, Werther G, Warne G, Adler R, Andrewes D. Neuropsychological complications of insulin dependent diabetes in children two years after disease onset. Diabetes Care 1998;21:379-84.

[18] Killiany R], Hyman BT, Comez-Isla T, Moss MB, Kikinis R, Jolesz F, et al. MRI measures of entorhinal cortex vs hippocampus in preclinical AD. Neurology 2002;58:1188-96.

[19] Duara R, Loewenstein DA, Potter E, Appel ], Greig MT, Urs R, et al. Medial temporal lobe atrophy on MRI scans and the diagnosis of Alzheimer disease. Neurology 2008;71:1986-92.

[20] Kivipelto M, Mangialasche F, Ngandu T. Lifestyle interventions to prevent cognitive impairment, dementia and Alzheimer disease. Nat Rev Neurol 2018;14:653-66.

[21] Shan Z, Li Y, Zong G, Guo Y, Li ], Manson ]E, et al. Rotating night shift work and adherence to unhealthy lifestyle in predicting risk of type 2 diabetes: results from two large US cohorts of female nurses. Br Med ] 2018;363:k4641.

[22] Mirowsky ]. Cognitive decline and the default American lifestyle. ] Gerontol B Psychol Sci Soc Sci 2011;66B:i50-8.

[23] The GBD 2015 Obesity Collaborators, Afshin A, Forouzanfar MH, Reitsma MB, Sur P, Estep Ket al. Health effects of overweight and obesity in 195 countries over 25 years. N Engl ] Med 2017;377:13-27.

[24] Lee H], Seo HI, Cha HY, Yang Y], Kwon SH, Yang S]. Diabetes and Alzheimer's disease: mechanisms and nutritional aspects. Clin Nutr Res 2018;7:229-40. 
[25] Solfrizzi V, Panza F, Frisardi V, Seripa D, Logroscino G, Imbimbo BP, et al. Diet and Alzheimer's disease risk factors or prevention: the current evidence. Expert Rev Neurother 2011;11:677-708.

[26] Flanagan E, Muller M, Hornberger M, Vauzour D. Impact of flavonoids on cellular and molecular mechanisms underlying age-related cognitive decline and neurodegeneration. Curr Nutr Rep 2018;7:49-57.

[27] Khan H, Marya, Amin S, Kamal MA, Patel S. Flavonoids as acetylcholinesterase inhibitors: current therapeutic standing and future prospects. Biomed Pharmacother 2018;101:860-70.

[28] Naninck EF, Oosterink JE, Yam KY, de Vries LP, Schierbeek H, van Goudoever ]B, et al. Early micronutrient supplementation protects against early stress-induced cognitive impairments. FASEB ] 2017;31:505-18.

[29] Dik MC, Jonker C, Comijs HC, Deeg D], Kok A, Yaffe K, et al. Contribution of metabolic syndrome components to cognition in older individuals. Diabetes Care 2007;30:2655-60.

[30] Rhee SY, Kim YS. The role of advanced glycation end products in diabetic vascular complications. Diabetes Metab ] 2018;42:188-95.

[31] Yamagishi S, Imaizumi T. Diabetic vascular complications: pathophysiology, biochemical basis and potential therapeutic strategy. Curr Pharm 2005;11:2279-99.

[32] Strachan MW. R D Lawrence Lecture 2010. The brain as a target organ in type 2 diabetes: exploring the links with cognitive impairment and dementia. Diabet Med 2011;28:141-7.

[33] Koska ], Saremi A, Howell S, Bahn G, De Courten B, Ginsberg H, et al. Advanced glycation end products, oxidation products, and incident cardiovascular events in patients with type 2 diabetes. Diabetes Care 2018;41:570-6.

[34] Vanhanen M, Koivisto K, Kuusisto ], Mykkanen L, Helkala EL, Hänninen T, et al. Cognitive function in an elderly population with persistent impaired glucose tolerance. Diabetes Care 1998;21:398-402.

[35] Kuusisto ], Koivisto K, Mykkanen L, Helkala EL, Vanhanen M, Hänninen T, et al. Association between features of the insulin resistance syndrome and Alzheimer's disease independently of apolipoprotein E4 phenotype: cross-sectional population based study. BM] 1997;315:1045-9.

[36] Appleton JP, Scutt P, Sprigg N, Bath PM. Hypercholesterolaemia and vascular dementia. Clin Sci 2017;131:1561-78.

[37] Burgess BL, Mclsaac SA, Naus KE, Chan JY, Tansley CH, Yang ], et al. Elevated plasma triglyceride levels precede amyloid deposition in Alzheimer's disease mouse models with abundant A beta in plasma. Neurobiol Dis 2006;24:114-27.

[38] Xue H, Sun Q, Liu L, Zhou L, Liang R, He R, et al. Risk factors of transition from mild cognitive impairment to Alzheimer's disease and death: a cohort study. Compr Psychiatry 2017;78:91-7.

[39] Helzner EP, Luchsinger JA, Scarmeas N, Cosentino S, Brickman AM, Glymour MM, et al. Contribution of vascular risk factors to the progression in Alzheimer disease. Arch Neurol 2009;66:343-8.

[40] Barrientos RM, Kitt MM, Watkins LR, Maier SF. Neuroinflammation in the normal aging hippocampus. Neuroscience 2015;309:84-99.

[41] Beilharz JE, Maniam ], Morris M]. Short-term exposure to a diet high in fat and sugar, or liquid sugar, selectively impairs hippocampaldependent memory, with differential impacts on inflammation. Behav Brain Res 2016;306:1-7.

[42] Denver P, Gault VA, McClean PL. Sustained high-fat diet modulates inflammation, insulin signalling and cognition in mice and a modified xenin peptide ameliorates neuropathology in a chronic high-fat model. Diabetes Obes Metab 2018;20:1166-75.

[43] Cholerton B, Baker LD, Montine T], Craft S. Type 2 diabetes, cognition, and dementia in older adults: toward a precision health approach. Diabetes Spectr 2016;29:210-9.

[44] Feinkohl I, Price JF, Strachan MW, Frier BM. The impact of diabetes on cognitive decline: potential vascular, metabolic, and psychosocial risk factors. Alzheimers Res Ther 2015;7:46.

[45] Chaytor NS. Cognition in adults and older adults with type 1 diabetes: chicken or egg? Diabetes Spectr 2016;29:219-24.

[46] Spencer S], Korosi A, Laye S, Shukitt-Hale B, Barrientos RM. Food for thought: how nutrition impacts cognition and emotion. NP] Sci Food 2017;1:7.

[47] Moreira MC, Piazzon FB, Carvalho MD, Quaio CR, Dutra AB, Ceccon ME, et al. A dominant ABCC8-related hyperinsulinism: familial case report. ABCC8-related hyperinsulinism. Fetal Pediatr Pathol 2013;32:384-6.

[48] Reyes AE, Chacon MA, Dinamarca MC, Cerpa W, Morgan C, Inestrosa NC. Acetylcholinesterase-Abeta complexes are more toxic than Abeta fibrils in rat hippocampus: effect on rat beta-amyloid aggregation, laminin expression, reactive astrocytosis, and neuronal cell loss. Am J Pathol 2004;164:2163-74.

[49] Yang WN, Han H, Hu XD, Feng CF, Qian YH. The effects of perindopril on cognitive impairment induced by d-galactose and aluminum trichloride via inhibition of acetylcholinesterase activity and oxidative stress. Pharmacol Biochem Behav 2013;114-115:31-6.

[50] Barnes ]N, Joyner M]. Sugar highs and lows: the impact diet on cognitive function.] Physiol 2012;15:28-31.

[51] Massoulie ], Sussman ], Bon S, Silman I. Structure and functions of acetylcholinesterase and buturycholinesterase. Prog Brain Res 1993;98:139-46.

[52] Yamamoto N, Yamanka C, Takasugi E, Ishikawa M, Yamanaka T, Murakami S, et al. Lifestyle intervention reversed cognitive function in aged people with diabetes mellitus: two year follow up. Diabetes Res Clin Pract 2009;85:343-6.

[53] Hu FB, Manson ]E, Stampfer M], Colditz G, Liu S, Solomon CG, et al. Diet, lifestyle, and the risk of type 2 diabetes mellitus in women. N Engl ] Med 2001;345:790-7.

[54] Morrison ]H, Baxter MG. The ageing cortical synapse: hallmarks and implications for cognitive decline. Nat Rev Neurosci 2012;13:24050.

[55] Shi Q, Colodner K], Matousek SB, Merry K, Hong S, Kenison JE, et al. Lemere Complement C3-deficient mice fail to display age-related hippocampal decline. J Neuroscim 2015;35:13029-42.

[56] Vasto S, Barera A, Rizzo C, Di Carlo M, Caruso C, Panotopoulos C. Mediterranean diet and longevity: an example of nutraceuticals? Curr Vasc Pharmacol 2014;12:735-8.

[57] Greca M, Zarrelli A. Nutraceuticals and Mediterranean diet. Med Aromat Plants 2012;1:e126

[58] Ceorgoulis M, Kontogianni MD, Yiannakouris N. Mediterranean diet and diabetes: prevention and treatment. Nutrients 2014;6:1406-23.

[59] Bazinet RP, Laye S. Polyunsaturated fatty acids and their metabolites in brain function and disease. Nat Rev Neurosci 2014;15:771-85. 
[60] Laye S, Nadiar A, Joffre C, Bazinet RP. Anti-inflammatory effects of omega-3 fatty acids in the brain: physiological mechanisms and relevance to pharmacology. Pharmacol Rev 2018;70:12-38.

[61] Dyall SC. Long-chain omega-3 fatty acids and the brain: a review of the independent and shared effects of EPA, DPA and DHA. Front Aging Neurosci 2015;7:52.

[62] Hashimoto M, Maekawa M, Katakura M, Hamazaki K, Matsuoka Y. Possibility of polyunsaturated fatty acids for the prevention and treatment of neuropsychiatric illnesses. ] Pharmacol Sci 2014;124:294-300.

[63] Cutuli D, De Bartolo P, Caporali P, Laricchiuta D, Foti F, Ronci M, et al. n-3 polyunsaturated fatty acids supplementation enhances hippocampal functionality in aged mice. Front Aging Neurosci 2014;6:1-17.

[64] Yurko-Mauro K, Alexander DD, Van Elswyk ME. Docosahexaenoic acid and adult memory: a systematic review and meta-analysis. PLoS One 2015;10:e0120391.

[65] Fotuhi M, Mohassel P, Yaffe K. Fish consumption, long-chain omega-3 fatty acids and risk of cognitive decline or Alzheimer disease: a complex association. Nat Clin Pract Neurol 2009;5:140-52.

[66] Denis I, Potier B, Vancassel S, Heberden C, Lavialle M. Omega-3 fatty acids and brain resistance to ageing and stress: body of evidence and possible mechanisms. Ageing Res Rev 2013;12:579-94.

[67] Lee LK, Shahar S, Chin AV, Yusoff NAM. Docosahexaenoic acid-concentrated fish oil supplementation in subjects with mild cognitive impairment (MCl): a 12-month randomised, double-blind, placebo-controlled trial. Psychopharmacol 2013;225:605-12.

[68] Kotani S, Sakaguchi E, Warashina S, Matsukawa N, Ishikura Y, Kiso Y. Dietary supplementation of arachidonic and docosahexaenoic acids improves cognitive dysfunction. Neurosci Res 2006;56:159-64.

[69] Kravitz E, Schmeidler ], Beeri MS. Type 2 diabetes and cognitive compromise: potential roles of diabetes-related therapies. Endocrinol Metab Clin North Am 2013;42:489-501.

[70] Devore EE, Kang JH, Breteler MM, Grodstein F. Dietary intakes of berries and flavonoids in relation to cognitive decline. Ann Neurol 2012;72:135-43.

[71] Stevenson DE, Hurst RD. Polyphenolic phytochemicals - just antioxidants or much more? Cell Mol Life Sci 2007;64:2900-16.

[72] Solanki I, Parihar P, Mansuri ML, Parihar MS. Flavonoid-based therapies in the early management of neurodegenerative diseases. Adv Nutr 2015;6:64-72.

[73] Solanki I, Parihar P, Parihar MS. Neurodegenerative diseases: from available treatments to prospective herbal therapy. Neurochem Int 2016;95:100-8.

[74] Parihar P, Parihar MS. Metabolic enzymes dysregulation in heart failure: the prospective therapy. Heart Fail Rev 2017;22:109-21.

[75] Parihar A, Parihar MS. Bioactive food components in the prevention of cardiovascular diseases. In: Mérillon JM, Ramawat K, editors. Bioactive molecules in food. Reference series in phytochemistry. Cham, Switzerland: Springer, 2017:1-21.

[76] Sheng R, Lin X, Zhang ], Chol KS, Huang W, Yang B, et al. Design, synthesis and evaluation of flavonoid derivatives as potent AChE inhibitors. Bioorg Med Chem 2009;17:6692-8.

[77] Hertog MG, Hollman PC, Van De PB. Content of potentially anticarcinogenic flavonoids of tea infusions, wines, and fruit juices. ] Agric Food Chem 1993;41:1242-6.

[78] Justesen U, Knuthsen P. Composition of flavonoids in fresh herbs and calculation of flavonoid intake by use of herbs in traditional Danish dishes. Food Chem 2001;73:245-50.

[79] Stewart A], Bozonnet S, Mullen W, Jenkins CI, Lean ME, Crozier A. Occurrence of flavonols in tomatoes and tomato-based products. ] Agric Food Chem 2000;48:2663-9.

[80] Zheng W, Wang SY. Antioxidant activity and phenolic compounds in selected herbs. ] Agric Food Chem 2001;49:5165-70.

[81] Atanassova M, Bagdassarian V. Rutin content in plant products. ] Univ Chem Tech Met 2009;44:201-3.

[82] Chang S, Tan C, Frankel EN, Barrett DM. Low-density lipoprotein antioxidant activity of phenolic compounds and polyphenol oxidase activity in selected clingstone peach cultivars. J Agric Food Chem 2000;48:147-51.

[83] Malagutti AR, Zuin V, Cavalheiro E, Mazo LH. Determination of rutin in green tea infusions using square wave voltammetry with a rigid carbon-polyurethane composite electrode. Electroanalysis 2006;18:1028-34.

[84] Calderon-Montano JM, Burgos-Moron E, Perez-Guerrero C, López-Lázaro M. A review on the dietary flavonoid kaempferol. Mini Rev Med Chem 2011;11:298-344.

[85] Liu RH. Health-promoting components of fruits and vegetables in the diet. Adv Nutr 2013;4:384S-392S

[86] Kim SH, Choi KC. Anti-cancer effect and underlying mechanism(s) of kaempferol, a phytoestrogen, on the regulation of apoptosis in diverse cancer cell models. Toxicol Res 2013;29:229-34.

[87] Khan MT, Orhan I, Enol SS. Cholinesterase inhibitory activities of some flavonoid derivatives and chosen xanthone and their molecular docking studies. Chem Biol Interact 2009;181:383-9.

[88] Wang W, Wang F, Yang Y], Hu ZL, Long LH, Fu H, et al. The flavonoid baicalein promotes NMDA receptor-dependent long-term potentiation and enhances memory. Br] Pharmacol 2011;162:1364-79.

[89] Coto T, Teraminami A, Lee JY, Ohyama K, Funakoshi K, Kim YI, et al. Tiliroside, a glycosidic flavonoid, ameliorates obesity-induced metabolic disorders via activation of adiponectin signaling followed by enhancement of fatty acid oxidation in liver and skeletal muscle in obese-diabetic mice. J Nutr Biochem 2012;23:768-76.

[90] Medjakovic S, Jungbauer A. Red clover isoflavones biochanin A and formononetin are potent ligands of the human aryl hydrocarbon receptor. J Steroid Biochem Mol Biol 2008;108:171-7.

[91] Felgines C, Texier O, Morand C, Manach C, Scalbert A, Régerat F. Bioavailability of the flavanone naringenin and its glycosides in rats. Am ] Physiol Gastrointest Liver Physiol 2000;279:G1148-54.

[92] Patel K, Singh CK, Patel DK. A review on pharmacological and analytical aspects of naringenin. Chin ] Integr Med 2018;24:551-60.

[93] Thompson LU, Boucher BA, Liu Z, Cotterchio M, Kreiger N. Phytoestrogen content of foods consumed in Canada, including isoflavones, lignans, and coumestan. Nutr Cancer 2006;54:184-201.

[94] Umpress ST, Murphy SP, Franke AA, Custer L], Blitz CL. Isoflavone content of foods with soy additives. J Food Comp Anal 2005;18:533-50. 
[95] Krenn L, Unterrieder I, Ruprechter R. Quantification of isoflavones in red clover by high-performance liquid chromatography.] Chromatogr B 2002;777:123-8.

[96] Coward L, Barnes NC, Setchell KD, Barnes S. Cenistein, daidzein, and their $\beta$-glycoside conjugates: antitumor isoflavones in soybean foods from American and Asian diets. J Agric Food Chem 1993;41:1961-7.

[97] Shimoi K, Okada H, Furugori M, Coda T, Takase S, Suzuki M, et al. Intestinal absorption of luteolin and luteolin 7-O- $\beta$-glucoside in rats and humans. FEBS Lett 1998;438:220-4.

[98] Lopez-Lazaro M. Distribution and biological activities of the flavonoid luteolin. Mini Rev Med Chem 2009;9:31-59.

[99] Andreeva OA, Ivashev MN, Ozimina II, Maslikova CV. Diosmetin glycosides from Caucasian vetch: isolation and study of biological activity. Pharm Chem ] 1998;32:595-7.

[100] Duan S, Guan X, Lin R, Liu X, Yan Y, Lin R, et al. Silibinin inhibits acetylcholinesterase activity and amyloid $\beta$ peptide aggregation: a dual-target drug for the treatment of Alzheimer's disease. Neurobiol Aging 2015;36:1792-807.

[101] Lutz ]A, Carter M, Fields L, Barron S, Littleton JM. The dietary flavonoid rhamnetin inhibits both inflammation and excitotoxicity during ethanol withdrawal in rat organotypic hippocampal slice cultures. Alcohol Clin Exp Res 2015;39:2345-53.

[102] Olennikov DN, Kashchenko NI, Chirikova NK, Akobirshoeva A, Zilfikarov IN, Vennos C. Isorhamnetin and quercetin derivatives as antiacetylcholinesterase principles of marigold (Calendula officinalis) flowers and preparations. Int ] Mol Sci 2017;18:1685.

[103] Wagner H, Ertan M, Seligmann O. Rhamnazin- und rhamnetin-3-O-trioside aus Rhamnus petiolaris. Phytochemistry 1974;13:857-60.

[104] Rodriguez-Mateos A, Vauzour D, Krueger CC, Shanmuganayagam D, Reed ], Calani L, et al. Bioavailability, bioactivity and impact on health of dietary flavonoids and related compounds: an update. Arch Toxicol 2014;88:1803-53.

[105] Brickman AM, Khan UA, Provenzano FA, Yeung LK, Suzuki W, Schroeter H, et al. Enhancing dentate gyrus function with dietary flavanols improves cognition in older adults. Nat Neurosci 2014;17:1798-803.

[106] Scholey AB, French S], Morris P], Kennedy DO, Milne AL, Haskell CF. Consumption of cocoa flavanols results in acute improvements in mood and cognitive performance during sustained mental effort. J Psychopharmacol 2010;24:1505-14.

[107] Wightman EL, Haskell CF, Forster ]S, Veasey RC, Kennedy DO. Epigallocatechin gallate, cerebral blood flow parameters, cognitive performance and mood in healthy humans: a double-blind, placebo-controlled, crossover investigation. Hum Psychopharmacol 2012;27:177-86.

[108] Joseph JA, Shukitt-Hale B, Denisova NA, Bielinski D, Martin A, McEwen ]], et al. Reversals of age-related declines in neuronal signal transduction, cognitive, and motor behavioral deficits with blueberry, spinach, or strawberry dietary supplementation. J Neurosci 1999;19:8114-21.

[109] Miller MG, Shukitt-Hale B. Berry fruit enhances beneficial signaling in the brain. J Agric Food Chem 2012;60:5709-15.

[110] Bowtell ]L, Aboo-Bakkar Z, Conway ME, Adlam AR, Fulford ]. Enhanced task-related brain activation and resting perfusion in healthy older adults after chronic blueberry supplementation. Appl Physiol Nutr Metab 2017;42:773-9.

[111] Whyte AR, Williams CM. Effects of a single dose of a flavonoid-rich blueberry drink on memory in 8 to 10 years old children. Nutrition 2015;31:531-4.

[112] Whyte AR, Schafer G, Williams CM. Cognitive effects following acute wild blueberry supplementation on 7- to 10-year-old children. Eur ] Nutr 2016;55:2151-62.

[113] Goyarzu P, Malin DH, Lau F, Taglialatela G, Moon WD, Jennings R. Blueberry supplemented diet: effects on object recognition memory and nuclear factor-kappa B levels in aged rats. Nutr Neurosci 2004;7:75-83.

[114] Dias AS, Porawski M, Alonso M, Marroni N, Collado PS, Conzalez-Gallego ]. Quercetin decreases oxidative stress, NF-kappaB activation, and iNOS overexpression in liver of streptozotocin-induced diabetic rats. J Nutr 2005;135:2299-304.

[115] Shukitt-Hale B, Carey AN, Jenkins D, Rabin BM, Joseph JA. Beneficial effects of fruit extracts on neuronal function and behavior in a rodent model of accelerated aging. Neurobiol Aging 2007;28:1187-94.

[116] Krikorian R, Nash TA, Shidler MD, Shukitt-Hale B, Joseph JA. Concord grape juice supplementation improves memory function in older adults with mild cognitive impairment. Br] Nutri 2010;103:730-4.

[117] Caldwell K, Charlton KE, Roodenrys S, Jenner A. Anthocyanin-rich cherry juice does not improve acute cognitive performance on RAVLT. Nutr Neurosci 2016;19:423-4.

[118] Alharbi MH, Lamport D], Dodd GF, Saunders C, Harkness L, Butler LT. Flavonoid rich orange juice is associated with acute improvements in cognitive function in healthy middle-aged males. Eur ] Nutr 2016;55:2021-9.

[119] Shukitt-Hale B, Cheng V, Joseph ]A. Effects of blackberries on motor and cognitive function in aged rats. Nutri Neurosci 2009;12:135-40.

[120] Shih PH, Chan YC, Liao JW, Wang MF, Yen CC. Antioxidant and cognitive promotion effects of anthocyanin-rich mulberry (Morus atropurpurea L.) on senescence-accelerated mice and prevention of Alzheimer's disease. J Nutri Biochem 2010;21:598-605.

[121] Miller MG, Thangthaeng N, Poulose SM, Shukitt-Hale B. Role of fruits, nuts, and vegetables in maintaining cognitive health. Exp Cerontol 2017;94:24-8.

[122] Lamport D], Saunders C, Butler LT, Spencer ]P. Fruits, vegetables, 100\% juices, and cognitive function. Nutri Rev 2014;72:774-89.

[123] Williams R], Spencer JP. Flavonoids, cognition, and dementia: actions, mechanisms, and potential therapeutic utility for Alzheimer disease Free. Radic Biol Med 2012;52:35-45.

[124] Williams R], Spencer JP, Rice-Evans C. Flavonoids: antioxidants or signalling molecules? Free Radic Biol Med 2004;36:838-49.

[125] Vauzour D. Dietary polyphenols as modulators of brain functions: biological actions and molecular mechanisms underpinning their beneficial effects. Oxid Med Cell Longev 2012;2012:914273.

[126] Spencer]P, Vafeiadou K, Williams R], Vauzour D. Neuroinflammation: modulation by flavonoids and mechanisms of action. Mol Asp Med 2012;33:83-97.

[127] Vafeiadou K, Vauzour D, Lee HY, Rodriguez-Mateos A, Williams R], Spencer ]P. The citrus flavanone naringenin inhibits inflammatory signalling in glial cells and protects against neuroinflammatory injury. Arch Biochem Biophys 2009;484:100-9.

[128] Nanri A, Yoshida D, Yamaji T, Mizoue T, Takayanagi R, Kono S. Dietary patterns and C-reactive protein in Japanese men and women. Am J Clin Nutr 2008;85:1488-96. 
[129] Chun OK, Chung S], Claycombe K], Song WO. Serum C-reactive protein concentrations are inversely associated with dietary flavonoid intake in U.S. adults. ] Nutr 2008;138:753-60.

[130] Karlsen A, Retterstol L, Laake P, Paur I, Bohn SK, Sandvik L, et al. Anthocyanins inhibit nuclear factor-kappaB activation in monocytes and reduce plasma concentrations of pro-inflammatory mediators in healthy adults. J Nutr 2007;137:1951-4.

[131] Parihar A, Parihar MS, Milner S, Bhat S. Oxidative stress and anti-oxidative mobilization in burn injury. Burns 2008;34:6-17.

[132] Hemnani T, Parihar MS. Reactive oxygen species and oxidative DNA damage. Indian ] Physiol Pharmacol 1998;42:440-52.

[133] Brownlee M. Biochemistry and molecular cell biology of diabetic complications. Nature 2001;414:813-20.

[134] Van Dyk K, Sano M. The impact of nutrition on cognition in the elderly. Neurochem Res 2007:32:893-904.

[135] Dore S. Unique properties of polyphenol stilbenes in the brain: more than direct antioxidant actions; gene/protein regulatory activity. Neurosignals 2005;14:61-70.

[136] Sarubbo F, Ramis MR, Kienzer C, Aparicio S, Esteban S, Miralles A, et al. Chronic silymarin, quercetin and naringenin treatments increase monoamines synthesis and hippocampal Sirt1 levels improving cognition in aged rats. J Neuroimmune Pharmacol 2018;13:24-38.

[137] Sandoval-Acuna C, Ferreira ], Speisky H. Polyphenols and mitochondria: an update on their increasingly emerging ROS-scavenging independent actions. Arch Biochem Biophys 2014;559:75-90.

[138] Pandey KB, Rizvi SI. Plant polyphenols as dietary antioxidants in human health and disease. Oxid Med Cell Longev 2009;2:270-8.

[139] Parihar P, Solanki I, Mansuri ML, Parihar MS. Mitochondrial sirtuins: emerging roles in metabolic regulations, energy homeostasis and diseases. Exp Cerontol 2015; 61:130-41.

[140] Ahmed SM, Luo L, Namani A, Wang X], Tang X. Nrf2 signaling pathway: pivotal roles in inflammation. Biochim Biophys Acta Mol Basis Dis 2017;1863:585-97.

[141] Chao MV. Neurotrophins and their receptors: a convergence point for many signalling pathways. Nat Rev Neurosci 2003;4:299-309.

[142] Kerimi A, Williamson C. At the interface of antioxidant signalling and cellular function: key polyphenol effects. Mol Nutr Food Res 2016;60:1770-88.

[143] Nones ], E Spohr TC, Comes FC. Hesperidin, a flavone glycoside, as mediator of neuronal survival. Neurochem Res 2011;36:1776-84.

[144] Claude S, Boby C, Rodriguez-Mateos A, Spencer ]P, Cérard N, Morand C, et al. Flavanol metabolites reduce monocyte adhesion to endothelial cells through modulation of expression of genes via p38-MAPK and p65-Nf-kB pathways. Mol Nutr Food Res 2014;58:1016-27.

[145] Russo CL, Russo M, Spagnuolo C. The pleiotropic flavonoid quercetin: from its metabolism to the inhibition of protein kinases in chronic lymphocytic leukemia. Food Funct 2014;5:2393-401.

[146] Dai X, Ding Y, Zhang Z, Cai X, Li Y. Quercetin and quercitrin protect against cytokine induced injuries in RINm5F beta-cells via the mitochondrial pathway and NF-kappaB signaling. Int ] Mol Med 2013;31:265-71.

[147] Impey S, Obrietan K, Wong ST, Poser S, Yano S, Wayman G, et al. Cross talk between ERK and PKA is required for Ca2+ stimulation of CREB-dependent transcription and ERK nuclear translocation. Neuron 1998;21:869-83.

[148] Schroeter H, Bahia P, Spencer ]P, Sheppard O, Rattray M, Cadenas E, et al. Epicatechin stimulates ERK-dependent cyclic AMP response element activity and up-regulates GluR2 in cortical neurons. J Neurochem 2007;101:1596-606.

[149] Vauzour D, Vafeiadou K, Rice-Evans C, Williams R], Spencer ]P. Activation of pro-survival Akt and ERK1/2 signalling pathways underlie the anti-apoptotic effects of flavanones in cortical neurons. J Neurochem 2007;103:1355-67.

[150] Cheng A, Wang S, Cai ], Rao MS, Mattson MP. Nitric oxide acts in a positive feedback loop with BDNF to regulate neural progenitor cell proliferation and differentiation in the mammalian brain. Dev Biol 2003;258:319-33.

[151] Askari H, Abazari MF, Choraeian P, Torabinejad S, Nouri Aleagha M, Mirfallah Nassiri R, et al. Ameliorative effects of hydrogen sulfide (NaHS) on chronic kidney disease-induced brain dysfunction in rats: implication on role of nitric oxide (NO) signaling. Metab Brain Dis 2018;33:1945-54.

[152] de la Torre JC, Aliev C. Inhibition of vascular nitric oxide after rat chronic brain hypoperfusion: spatial memory and immunocytochemical changes. J Cereb Blood Flow Metab 2005;25:663-72.

[153] Mueller M, Lukas B, Novak ], Simoncini T, Genazzani AR, Jungbauer A. Oregano: a source for peroxisome proliferator-activated receptor gamma antagonists. J Agric Food Chem 2008; I56:11621-30.

[154] Andres-Lacueva C, Shukitt-Hale B, Gilli RL, Jauregui O, Lamuela Raventos RM, Joseph ]A. Anthocyanins in aged blueberry-fed rats are found centrally and may enhance memory. Nutr Neurosci 2005;8:111-20. 